\title{
A emergência dos Black Blocs \\ no contexto das jornadas de junho de 2013 no Brasil: da tática de resistência ao movimento social
}

\author{
The emergence of black blocs \\ in the context of 2013 june days in Brazil: \\ the strength of tactics to social movement
}

\author{
Vanessa de Souza Hacon \\ Doutoranda em Ciências Sociais (Universidade Federal do Rio de Janeiro) \\ vanessahacon@gmail.com
}

\begin{abstract}
Resumo: O presente artigo propõe-se a debater o ciclo de protestos e confrontos ocorridos a partir do mês de junho de 2013, em diversas cidades no Brasil, naquilo que ficou conhecido como as Jornadas de Junho, destacando a emergência dos black blocs enquanto tática de resistência e luta. Nesse sentido, busca discutir a atuação deste quase grupo na sua relação com os movimentos sociais e novas possibilidades de organização social e política, apontando para a necessidade da construção de novas teorias dos movimentos sociais capazes de abarcar novas situações históricas e fenômenos alicerçados sobre bases conjunturais diversas.
\end{abstract}

Palavras-chave: Jornadas de Junho. Black Blocs. Quase grupos. Teoria dos movimentos sociais. Conflito.

\begin{abstract}
This article aims to discuss the cycle of protests and clashes started from the month of June 2013 on, in various cities in Brazil, in what became known as the June Journeys, highlighting the emergence of black blocs as a tactic of resistance and struggle. Thus, it seeks to discuss the performance of this quasi-group in its relationship with social movements and new possibilities for social and political organization, pointing to the need for new theories regarding social movements capable of embracing new historical situations and phenomena grounded on diverse conjuntural basis.
\end{abstract}

Keywords: June Journeys. Black Blocs. Quasi-groups. Theory of social movements. Conflict.

Originais recebidos em: 30/06/2015

Aceito para a publicação em: 28/07/2015

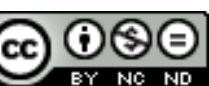

Este trabalho está licenciado sob uma Licença Creative Commons Atribuição-Uso NãoComercial-Vedada a criação de obras derivadas 3.0 Unported License. 


\section{O contexto de surgimento das Jornadas de Junho de 2013}

As mobilizações sociais de junho de 2013 ocorridas em todo o Brasil, com desdobramentos e prosseguimento nos meses subsequentes, tiveram seu estopim no aumento das tarifas de ônibus, ocorrido de forma orquestrada em todo o país, conjugado ainda à insatisfação generalizada associada aos gastos públicos com os megaeventos esportivos programados para o Brasil nos anos consecutivos ${ }^{1}$. O evento-símbolo e inaugurador desta nova fase foi a Copa das Confederações, realizada também no mês de junho de 2013 nos novos estádios recém-construídos em seis capitais-sede da Copa do Mundo de 2014. O evento, que deveria funcionar como teste e vitrine do Brasil para o mundo, acabou desdobrando-se em profunda indignação e revolta quanto aos altos gastos públicos direcionados para setores não exatamente prioritários em contraposição ao flagrante descaso com setores fundamentais como saúde e educação. O Brasil posicionava-se no cenário internacional como grande anfitrião do futebol, enquanto internamente os conflitos acirravam-se em um ritmo insuportável, alimentados pela crescente inflação, deterioração das condições de vida e de trabalho de grande parte da população, agudização da desigualdade social versus o aprofundamento da concentração de capital e casos flagrantes de beneficiamento privado por parte de entes públicos, tanto na esfera da legalidade quanto da ilegalidade. Sendo assim, estava posta uma pauta comum de luta por direitos coletivos considerados básicos, porém não ofertados de forma satisfatória pelo Estado, incluindo-se saúde, educação e mobilidade urbana, para citar apenas os mais emblemáticos. Pontualmente, é preciso destacar o protagonismo inicial do Movimento Passe Livre - MPL, responsável por convocar nacionalmente inúmeros atos públicos em protesto contra o aumento das passagens de ônibus. Em contrapartida, a repressão policial violenta e desproporcional contribuiu de modo significativo para impulsionar os protestos e aumentar a adesão popular aos mesmos, culminando nos atos de 20 junho espalhados por todo o país, em um total de 388 cidades incluindo 22 capitais (UOL, 2013) que, somente no Rio de Janeiro, lograram reunir mais de 1 milhão de manifestantes ${ }^{2}$.

\footnotetext{
${ }^{1}$ Sendo estes a Copa do Mundo, em 2014, sediada por 12 capitais brasileiras, e Jogos Olímpicos, em 2016, na cidade do Rio de Janeiro.

${ }^{2}$ Não é possível apresentar uma fonte para este dado tendo em vista a controvérsia entre as estatísticas oficiais, que subestimam largamente os números de participantes nos protestos, e a experiência vivida pela sociedade e retratada pelas mídias independentes e veiculadas pelas redes sociais. Contudo, para este ato, as estatísticas oscilaram entre 300.000 (oficial) e 2.000.000 de participantes.
}

Em Debat: Rev. Dig., ISSNe 1980-3532, Florianópolis, n. 12, p. 4-21, jun-dez, 2014. 
Logo ficou evidente que as pautas e os atores sociais eram muito mais amplos e variados do que se pressupunha. Tratava-se de uma catarse coletiva reunindo uma série de reivindicações e categorias sociais. Para falar da luta mais emblemática do início dos protestos - por transporte público gratuito e de qualidade -, havia por trás da mesma a reivindicação por transparência quanto aos valores investidos e lucrados pelas empresas de ônibus, haja vista a correlação cada vez mais explícita entre o notório financiamento de campanhas eleitorais com parte da receita arrecadada pelas empresas privadas de transporte "público" e os altos preços das passagens, em contínuo e frequente aumento. Portanto, não bastava apenas revogar o aumento das passagens (como eventualmente ocorreu, ainda que mediante o subsídio por parte do governo como forma de compensar as possíveis perdas financeiras das empresas de transporte), mas explicitar as conexões veladas que vêm influenciando desde o aumento do valor do transporte público - vis à vis à piora dos serviços ofertados, ao aumento dos custos associado à diminuição do poder aquisitivo da população, etc. - até a conformação e produção do espaço público baseadas na lógica privada, privilegiando determinados setores da sociedade em detrimento do bem estar das massas, inclusive ao arrepio da lei. Emergia, portanto, a luta de classes, démodé para alguns, mas absolutamente central na vida de milhares de outros, aguçada pelas últimas décadas de imposição de políticas neoliberais fracassadas e incapazes de prover o mínimo bem estar à população versus o seu aprofundamento crescente.

Do ponto de vista dos atores sociais, foi possível observar nas ruas desde a presença de movimentos sociais organizados e partidos políticos até manifestantes que se diziam "sem partido". Nesse sentido chamou a atenção um certo repúdio aos partidos políticos, enquanto categoria homogênea, em função da falta de identificação com os mesmos e incapacidade de se ver representado nas suas ações e estratégias políticas. Não cabe aqui discutir até que ponte esta crítica se aplica e até que ponto ela denota uma despolitização da sociedade resultante de décadas de implementação de políticas neoliberais, com desdobramentos nas várias esferas da vida, resultando na incorporação de uma nova pedagogia da hegemonia (NEVES, 2010). Cabe notar, porém, que tal crítica e a própria desilusão com o processo político, numa perspectiva mais ampla, devem ser levadas em consideração, inclusive para se entender o teor das mobilizações de junho. Nesse sentido, para além das grandes demonstrações de massa, talvez o maior fenômeno 
e inovação política deste período tenha sido a emergência dos black blocs, enquanto ação coletiva de protesto e resistência direta à repressão policial ${ }^{3}$.

\section{Os black blocs ou uma tática de resistência}

Embora autointitulados como "tática" de autodefesa e resistência composta por inúmeros grupos de procedências e naturezas distintas, em contraposição à noção mais tradicional de movimento social organizado, os black blocs não deixam de manifestar uma certa "homogeneidade", assim como conteúdo identificável, convergindo para uma noção de organização, mesmo que forjada nas ruas de forma improvisada. Nesse sentido, é possível destacar desde a sua prática de autodefesa - incluindo o confronto com as forças repressoras do Estado - até a sua atuação direta e conjunta contra símbolos do capitalismo, como, por exemplo, bancos, concessionárias de automóveis, sedes de grandes empresas, etc. Do ponto de vista performático, merece destaque o ato de cobrir o rosto com panos, assim como vestir-se, na sua maioria, em trajes negros, dando coesão ao grupo, ao menos no que tange à sua aparência. O fato de cobrir o rosto tem obviamente a sua funcionalidade, seja do ponto de vista do anonimato e impedimento à criminalização posterior dos manifestantes, seja do ponto de vista da proteção dos mesmos frente ao uso de bombas de gás lacrimogênio pela polícia. Porém, há também um elemento simbólico fundamental contido no ato de cobrir o rosto, qual seja, o de incorporar o sujeito coletivo da ação, descentralizando a sua origem e reunindo sob uma figura abstrata e anônima o sentido público da causa, sem que esta seja capturada por líderes que se sobressaiam à "agenda" coletiva, por mais fluida que esta possa parecer. O fato do discurso - e, em grande parte, a prática - privilegiar elementos como horizontalidade e autonomia, não significa dizer que não emerjam lideranças ou indivíduos que contribuam para a organização destes quase grupos (MAYER, 1987), ainda que de maneira ajustada às suas próprias condições transitórias.

Tratando-se da "agenda" expressa nas ações dos black blocs é possível apontar duas vertentes centrais: por um lado, uma luta anticapitalista, aprofundada pela versão neoliberal do sistema, responsável pelo acirramento das contradições sociais; e, por

\footnotetext{
${ }^{3}$ De fato, segundo Passetti (2013), esta não foi a primeira vez que esta forma de ação coletiva despontou em protestos no Brasil, podendo ser identificada desde as primeiras manifestações do movimento antiglobalização no país, no começo dos anos 2000. Contudo, seguramente, foi a partir dos protestos de junho de 2013 que esta "tática" ganhou visibilidade assim como os sujeitos desta ação passaram a ser identificados sob a denominação de "black blocs".
}

Em Debat: Rev. Dig., ISSNe 1980-3532, Florianópolis, n. 12, p. 4-21, jun-dez, 2014. 
outro, uma luta antiestatista, impulsionada pela desilusão com o processo político, pelas relações escusas entre Estado e capital, e pela resposta violenta do Estado às manifestações contrárias a todo este contexto (FERREIRA, 2013). Em outras palavras, há uma clara contestação à sobreposição dos interesses coletivos e públicos pelos interesses particulares e privados, e uma percepção de que a mercantilização das mais variadas esferas da vida resultou no aumento da extração de mais-valia sem necessariamente dar-se a contrapartida prometida. Esta insatisfação expressou-se em situações as mais distintas, variando da monopolização da informação por uma mídia cada vez mais concentrada nas mãos de alguns grupos econômicos e atrelada aos interesses da classe dominante até as remoções forçadas em virtude dos megaeventos e das megaobras do Programa de Aceleração do Crescimento - PAC do governo federal e seus impactos negativos gerados na cidade e no campo sobre os grupos vulnerabilizados.

Nesse sentido, este quase grupo, além de encampar muitas das bandeiras levantadas pelos manifestantes ao longo dos levantes populares de junho (e meses subsequentes), inaugurou o que podemos chamar de novos repertórios de luta, sem, contudo, reivindicar-se enquanto um movimento social organizado. Ao contrário, insiste na sua natureza heterogênea, destituída de líderes, pautada na reação (à opressão e à repressão) ao invés da ação, conformando um novo sujeito coletivo que se descobre e ao mesmo tempo se cria na sua prática de luta enquanto autodefesa ${ }^{4}$. Concomitantemente, se apoia em diversas contradições como, por exemplo, na sua tática vista como revolucionária em relação aos repertórios tradicionais dos partidos políticos e movimentos sociais versus a imposição de uma forma de agir que se sobrepõe a qualquer outra haja vista o uso da violência (que não lhes pode ser creditada diretamente, considerando-se que reagem em grande parte à ação da polícia e, diferentemente desta, não encontram-se armados, mas da qual tampouco se furtam). Ademais, encontra-se submetido ainda à sua própria natureza transitória, seja do ponto de vista da sua formação (enquanto duraram os protestos, aos quais se seguiu a dispersão dos indivíduos que formavam este quase grupo), seja do ponto de vista da sua constituição enquanto quase grupo (cuja consolidação acelerou-se a partir de junho de 2013, contando com adesão crescente, porém sem garantias de que perduraria na forma, número e manifestação observada em junho de 2013). Considerando-se tais argumentos,

\footnotetext{
${ }^{4}$ Algumas frases emblemáticas ajudam a entender esta identidade em formação: "Violento é o Estado" ou "Não confunda a reação do oprimido com a violência do opressor".
}

Em Debat: Rev. Dig., ISSNe 1980-3532, Florianópolis, n. 12, p. 4-21, jun-dez, 2014. 
de que modo é possível pensar este novo fenômeno social à luz dos debates referentes aos movimentos sociais e às estratégias de resistência cotidianas?

\section{Os "quase grupos" e coalizões}

Antes de iniciarmos a discussão referente a tais temas, é necessário explicitar o que se entende por quase grupos. A partir do debate da antropologia sobre as sociedades complexas e as distintas formas de interação entre os indivíduos presentes na mesma, alguns autores irão chamar a atenção para a emergência de novas categorias sociais a partir de situações específicas, efêmeras e não persistentes, cujo arranjo encontra-se igualmente subordinado a condições contingentes (MAYER, 1987; HARRIES-JONES, 1969). Nesse sentido, o conceito de quase grupos busca abranger uma série de manifestações sociais destas circunstâncias (nas figuras das coalizões, associações, facções), cujos elementos comuns são a sua condição transitória, ausência de uma estrutura identificável, onde é possível observar uma comunhão de interesses latentes, que, inclusive, podem vir a resultar na formação eventual de um grupo definido. Em virtude da elasticidade do conceito que inclui categorizações distintas (como, por exemplo, quase grupos classificatórios versus interativos), Boissevan (1971, p.470) irá optar pelo termo coalizão em substituição ao de quase grupos, definindo coalizão como "alianças temporárias de partes distintas em função de um propósito limitado".

Mayer, por sua vez, constrói um esquema teórico no qual submete as interações entre os indivíduos a uma sucessão de acontecimentos, iniciando-se do ego, passando pelos conjuntos-de-ação (action-sets), podendo desdobrar-se na formação de quase grupos. $\mathrm{O}$ ego tem papel fundamental, pois mobiliza as suas redes sociais pessoais de possíveis aliados para se atingir um determinado objetivo que se materializa em conjuntos-de-ação. Os conjuntos-de-ação são "formados por conexões derivadas de muitos campos sociais", mas, por orbitarem em torno do ego ou de vários egos (que, por sua vez, possuem um objetivo específico e mobilizam seus aliados para atingi-lo), tais conexões culminam por apresentar um traço comum (MAYER, 1987, p.154). Nesse sentido, o conjunto-de-ação "apresenta ramificações que unem as interconexões" (IBID, p.154). Contudo, por mais que seus membros estejam conscientes de que encontram-se reunidos para um propósito comum determinado e saibam que há outras interconexões semelhantes, podem não ser capazes de identificar cada uma das outras pessoas e coletivos envolvidos. 
Para Mayer, os conjuntos-de-ação não resultam automaticamente na formação de quase grupos, porém a ocorrência destes eventos de forma sucessiva e cumulativa em contextos similares pode gerar conexões e assim constituir um quase grupo (MAYER, 1987; BoISSEVAN, 1971). Enquanto Mayer opta pelo conceito de quase grupos, em função da sua capacidade de indicar as diferenças qualitativas existentes entre o grupo e o quase grupo e melhor expressar "as implicações sociológicas dessa espécie de agrupamento de indivíduos", Boissevan irá abandonar tal conceito por entender que é "logicamente incorreto considerar aliados em potencial enquanto constituintes de um quase grupo interativo" (MAYER, 1987, p. 164; BOISSEVAN, 1971, p.469). No seu lugar, privilegia a noção de coalizão, subordinando a efemeridade do processo aos interesses particulares dos variados indivíduos, o que acarreta, portanto, no abandono da causa em momentos distintos mediante a realização dos interesses de cada um dos envolvidos.

Nesse sentido, acreditamos que a definição mais abrangente de quase grupos encampada por Mayer nos seja mais apropriada no caso proposto para análise. Isto se dá, primeiramente, em função da existência de uma tática comum àqueles que se identificam como black blocs (mesmo que de forma momentânea e passageira), diferentemente, por exemplo, da adesão de indivíduos a uma campanha política onde cada um ocupará uma certa posição e buscará interesses particulares e distintos. Aqui, ao contrário, observa-se um conjunto de objetivos em comum, ainda que a "pauta de reivindicações" nem sempre seja explícita ou consciente. Em segundo lugar, coloca-se a própria dificuldade de amarrar conceitualmente um fenômeno em curso (sendo mais complicado, nesse caso, definí-lo por categorias específicas como facção, cliques ou coalizão, conforme sugerido por Harries-Jones [1969]). Por mais que concordemos com as críticas de Boissevan às limitações impostas pelo esquema teórico proposto por Mayer, no qual o mesmo estabelece um linha sucessória e interdependente entre o ego, os conjuntos-de-ação e a formação de quase grupos, entendemos que para os propósitos desta análise, o conceito de quase grupos (na sua própria condição circunstancial) nos basta.

Vale mencionar ainda que, mais recentemente, Tarrow (2005) apoiando-se em uma perspectiva sociológica, recorre ao termo coalizão, em substituição ao conceito de redes, para efetuar parte da sua análise das formas transnacionais de ativismo político. Nesse sentido, ademais de debruçar-se sobre o contexto específico da transnacionalização das lutas a partir de fins da década de 1990 e de situar-se no campo 
teórico dos debates referentes aos movimentos sociais, Tarrow dialoga com os teóricos e simpatizantes da noção de redes, popular no debate voltado para a política transnacional. No entanto, entende que o conceito de redes, dada a sua polissemia capaz de expressar desde um agrupamento intencional até outro estrutural (onde os indivíduos constituintes da rede podem estar absolutamente alheios à composição da mesma), é, por um lado, útil para mapear as potencialidades de formação de coalizões, porém insuficiente para analisar contextos mais singulares, onde ocorre apenas a formação intencional de agrupamentos. Logo, nesta perspectiva, define as coalizões como "arranjos colaborativos orientados para fins específicos que permitem entidades organizacionais distintas reunir recursos e esforços, a fim de efetuar a mudança" (TARROW, 2005, p. 164). Os fatores que levam os sujeitos (ou atores, como Tarrow coloca) a reunirem tais esforços são múltiplos e variados, porém incluem geralmente a conjunção de ameaças e oportunidades, com destaque para "a necessidade de unirem-se contra ameaças comuns" e o "ímpeto de produzir solidariedades entre os membros de categorias próximas" (IBID, p.164).

Ainda que Tarrow e Mayer transitem por caminhos um pouco diversos e se detenham, com maior ou menor atenção, a determinadas fases do processo, ambos buscam entender quando determinadas conexões intencionais se formarão, em que circunstâncias elas persistirão e o que isso implica em termos de formação de agrupamentos mais definidos ou movimentos sociais sustentados. Nesse sentido, não necessariamente os conjuntos-de-ação desdobrar-se-ão em quase grupos (MAYER, 1987), assim como as coalizões não necessariamente resultarão em movimentos sociais (TARROW, 2005).

\section{Os movimentos sociais e sua dinâmica relacional}

Sendo assim, pontuados alguns elementos pertinentes ao fenômeno social dos black blocs - emergente, sob esta denominação, no contexto brasileiro das Jornadas de Junho de 2013 - juntamente a uma tentativa de entender a organização desta coletividade posteriormente ao conjunto de protestos no período, nos resta pensar a sua inserção no debate mais amplo de movimentos sociais. De início, nos deparamos com algumas dificuldades metodológicas como a de enquadrar um fenômeno que se encontra em processo e, portanto, ainda não consolidado, haja vista os protestos subsequentes às Jornadas de Junho, incluindo-se aqueles ocorridos no mesmo ano assim como aqueles 
durante a Copa do Mundo, em 2014, até inúmeros outros que se apropriaram da "tática" dos black blocs enquanto forma de luta. Embora presente enquanto repertório de lutas e manifestações em outros locais do mundo, a adoção da tática combativa expressa nas ações dos black blocs enquanto cultura de protesto é algo relativamente recente no Brasil, ao menos sob esta denominação e gozando do grau de adesão obtido a partir do período observado. Nesse sentido, podemos dizer que inaugurou-se um novo padrão cultural de ação coletiva no país. Contudo, a própria condição transitória e efêmera da ação coletiva ou do movimento - se é que podemos chamá-lo assim - precisa ser levada em consideração para que o mesmo possa ser compreendido. Nesse sentido, entende-se que a apreensão do fenômeno deve se dar na sua condição de autoprodução.

Tarrow (2009), com sua abordagem da política confrontacional, legou à teoria social uma contribuição teórico-metodológica relacional e dinâmica reinserindo o conflito no centro da análise política (SANTOS, 2012). Na tentativa de superar a oposição entre ação e estrutura, expressa na dicotomia resistência versus autoridade, Tarrow define a noção de movimento social a partir de ciclos mais amplos de confronto sustentados entre grupos coordenados, de um lado, e elites, autoridades e oponentes, de outro, ampliando o conceito para incluir revoluções sociais, conflitos étnicos e ciclos de protesto (LINCHBACH, 1998). A partir dessa ampliação, incorpora a inovação em termos de repertórios de ação e formas associativas de modo a compreender a natureza dos movimentos sociais enquanto fenômeno histórico. Nesse sentido, reitera que o confronto político não surge por geração espontânea, mas encontra-se culturalmente inscrito e socialmente comunicado. Em outras palavras, determinados códigos culturais e contextos sociais são compartilhados numa espécie de pacto silencioso pelos indivíduos (que pode ou não observar determinados recortes, como, por exemplo, de classe), o que tampouco implica que elementos de convenção não possam ser combinados a novos quadros de significação resultando, por exemplo, em novos repertórios de luta (TARROW, 2009, p.40).

Da mesma forma que Thompson (1987) entende a classe como algo em processo que pode ou não consolidar-se, dependendo das condições históricas dadas em determinado período, Tarrow busca explicitar na sua noção de movimento social a noção de relação histórica. Para Tarrow (2009, p.249), “os movimentos se desenvolvem como interações específicas em fases gerais do confronto, dependendo das formas de mobilização que empregam, seus significados e identidades, e as redes sociais e estruturas conectivas sobre as quais são construídos". Logo, podem se consolidar 
enquanto tais ou não, dependendo das condições históricas. Assim, "o confronto se cristaliza em movimento social quando ele toca em redes sociais e estruturas conectivas embutidas e produz quadros interpretativos de ação coletiva e identidades de apoio capazes de sustentar o confronto com oponentes poderosos" (IBID, p.43). Nota-se nesta definição a importância da interação entre os oponentes, ou, em outros termos, a tensão entre estrutura (natureza do poder) e ação (constituição da resistência) (LINCHBACH, 1998; TILly, 1999). Dada a constituição recíproca e interdependente entre as estruturas estatais e os movimentos sociais, na qual "a autoridade gera a resistência que a transforma", o estudo do agenciamento dos protestos torna-se fundamental (LINCHBACH, 1998, p. 403). Nesta relação dialética, na qual o conflito ocupa um lugar estruturante, a observação e compreensão dos processos se dá a partir da forma como operam no tempo e no espaço e são conformados pelos sujeitos. Do mesmo modo Thompson, ao definir classe, destaca a necessidade da relação estar sempre encarnada em pessoas e contextos reais de modo a sermos capazes de identificar nas relações humanas existentes a ocorrência de determinado fenômeno:

Se detemos a história num determinado ponto, não há classes, mas
simplesmente uma multidão de indivíduos com um amontoado de
experiências. Mas se examinarmos esses homens durante um período
adequado de mudanças sociais, observaremos padrões em sua relações, suas
ideias e instituições. A classe é definida pelos homens enquanto vivem sua
própria história e, ao final, esta é a sua única definição. (THOMPSON, 1987, p.
11-12).

Tratam-se, portanto, de formações sociais e culturais e não de coisas em si ou categorias estáticas. Tanto Thompson quanto Tarrow reiteram a importância de se observar determinados processos quando eles operam durante um considerável período histórico. No caso do movimento social, a simples ocorrência de um número maior de eventos não basta para caracterizá-los como movimento social, sendo fundamental a percepção tanto por apoiadores quanto por oponentes de que tais eventos fazem parte de um movimento mais amplo e persistente (TARROW, 2009; TILLY, 1999). Tarrow (2009, p.250) destaca ainda que deve haver "mais do que uma 'atração' para formas particulares de ação coletiva; é preciso que haja também um 'impulso' de solidariedade e identidade coletiva". Nesse caso, a percepção e consolidação de uma identidade de interesses - ou identidade política - é fundamental para construir a coesão do grupo, levando-o a engajar-se na luta e sustentar-se no tempo. Da mesma forma que identidades coletivas preexistentes podem vir a beneficiar o movimento social, na medida em que este poderá canalizá-las e compatibilizá-las (SANTOS, 2012), novas 
identidades também são formadas no processo de confronto (TARROW, 2009), tratandose, portanto, de uma relação recíproca. Muito da construção do movimento se dá em torno de consensos alicerçados sobre significados e identidades comuns, sejam elas parcialmente herdadas ou construídas. Por outro lado, "é na luta que as pessoas descobrem quais são os valores que compartilham e quais os que os dividem", fazendo da interação entre ação coletiva, persistência das ameaças ou oportunidades, desenvolvimento de fortes identidades subjacentes, capacidade de organização e a própria oposição enfrentada elementos decisivos para se pensar a possibilidade de emergência dos movimentos sociais (TARROW, 2009, P. 158).

Portanto, do mesmo modo que Thompson insere o conflito no centro do seu conceito de classes, ao afirmar que a classe só pode ser entendida a partir da luta de classes, Tarrow desloca para o confronto o centro da sua teoria da ação coletiva, que inclui os movimentos sociais enquanto um subgênero. Nesse sentido, entende que "a melhor maneira de captá-los não é propondo leis gerais relativas ao confronto onde e quando ele ocorra, nem louvando a particularidade, mas examinando o poder em movimento" (TARROW, 2009, p. 248-249).

\section{A contestação: do neoliberalismo à noção de movimento social}

Sendo assim, partindo-se de uma perspectiva relacional e dinâmica para se entender os movimentos sociais, é possível afirmar que a emergência, persistência e certo protagonismo da "tática" dos black blocs nos ciclos de confronto observados a partir das Jornadas de Junho de 2013 trouxeram para o debate o próprio questionamento da noção de movimento social. Seguramente será necessário observar o desenvolvimento não apenas deste quase grupo ao longo do tempo - que quiçá poderá resultar na formação de uma organização, ou várias delas, capaz de traçar diretrizes comuns e linhas de ação conjuntas, ou, ao contrário, agregar novos sujeitos a organizações já preexistentes - mas também da sua capacidade de construção ou consolidação de uma identidade coletiva que contribua para a coesão do grupo assim como de obter adesão crescente, mantendo-se presente na cena pública. Do ponto de vista da conjuntura política, será necessário observar se as mudanças no futuro próximo serão favoráveis ou desfavoráveis às lutas sociais, provocando o engajamento ou a desmobilização. Contudo, apesar destes elementos serem importantes para identificarmos um movimento social, diferenciando-o, por exemplo, das resistências 
cotidianas ou de ações coletivas variadas (que, para alguns autores, não se traduzem automaticamente em movimento social), é preciso levar em conta que estamos diante de uma nova forma de ação coletiva que expressa também uma série de anseios e situações vivenciadas pelos sujeitos que contribuíram para conformar este repertório de luta enquanto tal. Em outras palavras, além da necessidade de protestar contra a ausência de serviços públicos de qualidade, a reconfiguração do espaço público pela lógica privada ou a truculência da força policial contra a sociedade, em especial contra as classes subalternas, há uma clara intenção de pautar a própria forma de ação política, refutando definitivamente a "esfera pública habermasiana" (fundada na noção de sociedade civil igualitária e democrática), assim como um modus operandi que se institucionalizou por parte de alguns movimentos e organizações sociais que pressupõe um modelo regulatório dos conflitos e a formação de espaços de negociação, com desdobramentos sobre a própria dinâmica da manifestação (pacífica, organizada e hierarquizada). Em última instância, recusa-se o pacto democrático e parte-se para a ação direta, não por uma incapacidade de dialogar, mas sim por uma exclusão, a priori, de determinados setores da sociedade localizados à margem desta suposta esfera democrática, acarretando na ação direta enquanto único recurso para se expressar e se fazer notar.

Assumindo-se uma resolução metodológica marxiana, se quisermos apreender o movimento de nosso objeto e reproduzi-lo idealmente, primeiro devemos pressupor o seu caráter transitório e dinâmico, o que implica no reconhecimento da inesgotabilidade natural do mesmo assim como em uma apreensão histórica e, portanto, sempre defasada do objeto. Por sua vez, a plena exposição do conteúdo dialético de determinado processo só é efetiva e historicamente possível quando este atinge um ponto de concretude, deixando de ser potência, onde o concreto torna-se processo já sintético (RANIERI, 1998). Nesse sentido, o ir-sendo do processo se apresenta como abstrato. É o método que "permite a articulação sintética como aquele momento do aparecer do concreto", desvelando as suas contradições por intermédio do movimento do pensamento que "se eleva do abstrato ao concreto, expondo este último como resultado" (RANIERI, 1998, p.158-159). Trata-se, contudo, de um concreto mediado, o que significa que sua complexidade não se encontra na sua imediatez e que seus elementos constituintes tampouco podem ser reconhecidos no âmbito fenomênico do objeto. Logo é necessário decompor seus elementos, "que são ao mesmo tempo abstratos e objetivantes" (RANIERI, 1998, p. 156), de modo a conhecê-lo. 
Feita esta ressalva, é necessário atentar para a necessidade de repensarmos os parâmetros utilizados para "definirmos" o processo, sob pena de nos perdermos na "tradução" do mesmo. James Scott (2002), na sua análise das formas de resistência cotidiana no campo, argumenta que, em determinados contextos, como, por exemplo, em muitos países do Terceiro Mundo, se buscarmos apenas nas organizações políticas formais os sinais de resistência camponesa às situações de opressão, exploração e expropriação, nada encontraremos, tendo em vista que nestes países tais organizações ou são inexistentes ou são criações oficiais e das elites rurais. Logo, seria ingênuo esperar que a resistência camponesa assumisse nestes contextos a mesma forma encontrada em países onde tal fração de classe goza de outra condição política, social e econômica. Nesse sentido, o uso de instrumentos de análise inapropriados levaria à leitura insuficiente da realidade. Scott defende então que "o que poderia faltar em termos de coordenação central poderia ser compensado em termos de flexibilidade e persistência" das ações (SCOTT, 2002, p.28). Por sua vez, as formas de atuação disponíveis também encontram-se diretamente dependentes das formas e níveis de repressão impostos, dada a relação dialética entre estrutura (dominação) e ação (resistência). Scott aponta ainda que aquilo que pode parecer como um conjunto de ações individuais descoordenadas não necessariamente o é. Nesse sentido, tudo depende do conceito de coordenação adotado, pois se tomarmos tal conceito do universo formal e burocrático não seremos capazes de identificar elementos como densas redes informais e subculturas de resistência, construídas sobre uma experiência histórica, de classe e identitária. Portanto, por vezes, as organizações formais não existem "pelo simples fato de não serem necessárias; concomitantemente, uma forma de coordenação é alcançada, alertando-nos para o fato de que o que está ocorrendo não é apenas uma ação individual" (SCOTT, 2002, p.29). Em outras palavras, há resistência em distintas escalas que, embora não possuam na sua aparência uma organização formal, encontramse "tacitamente organizadas e incentivadas pela cultura dos subalternos" (MonSMA, 2000, p. 100). Atinge-se, portanto, um “clima de opinião" que incorpora inclusive o não-dito ou os acordos silenciosos, que fazem das ações uma síntese das intenções.

Desse modo, ao pensarmos a "emergência" e "consolidação" dos black blocs nos ciclos de confronto iniciados nas Jornadas de Junho de 2013 e sua inserção em um conjunto mais amplo de movimentos sociais, devemos certamente observar determinados elementos que contribuem para "enquadrarmos" o fenômeno nas categorias de resistência cotidiana, ação coletiva ou movimento social. Porém, 
considerando-se que pretendemos capturar o poder em movimento, ou seja, o próprio processo de constituição da resistência em forma de grupo e/ou movimento social - que, conforme vimos, pode se dar ou não, dependendo das condições históricas - não podemos nos ater a categorias estáticas e contingentes sob pena de não apreendermos e, consequentemente, compreendermos tal processo. Estamos diante de um fenômeno que se alicerça sobre novas bases e situações históricas e que, portanto, demanda novas teorias. Em outras palavras, a ação direta (em alguns casos passível de criminalização) de grupos que podem ou não estar organizados e/ou associarem-se em função das circunstâncias formando um quase-grupo denota uma nova forma de resistência que anuncia também a possibilidade de novas formas de organização social e política. Nesse sentido, considerando-se, por exemplo, a crítica direcionada por setores combativos das massas (ou, se preferirem, setores eventualmente alinhados à tática dos black blocs nas Jornadas de Junho) às formas tradicionais de organização dos partidos políticos, à burocracia sindical e ao conservadorismo e centralização tanto do sindicalismo quanto de certos movimentos sociais considerados legalistas e oficialistas, seria enganoso esperar que os mesmos assumissem ou apresentassem formas de organização e ação análogas às das instituições que criticam $^{5}$. Isto não significa, contudo, um repúdio completo a certas formas de organização social (como, por exemplo, os sindicatos), mas sim um projeto de transformação destas instituições e suas formas de luta buscando romper com a cisão entre a base e setores que defendem a resistência e ação direta (o que, por sua vez, tampouco traduz uma "reivindicação" ou anseio dos black blocs agora sim enquanto um bloco coeso). Daí o apelo às formas não-hierarquizadas de organização, presença de horizontalidade nas relações e descentralização da ação que, em termos mais amplos, se traduzem em autonomia e liberdade do movimento, mas não implicam necessariamente em uma falta de direcionamento. $\mathrm{O}$ ato de cobrir o rosto, além da sua função objetiva de proteção à criminalização, é simbólica nesse sentido, pois horizontaliza as relações na medida em que homogeneíza os indivíduos sob uma única identidade anônima e impede a ascensão de um ou outro líder que venha a catalisar na sua figura individual uma causa que é coletiva ${ }^{6}$ (RECIFE RESISTE, 2013).

\footnotetext{
${ }^{5}$ Naquele que ficou conhecido como o Ato das Centrais Sindicais, no dia 11 de julho de 2013, no Rio de Janeiro, explicitaram-se as divergências entre setores com distintas formas de luta e protesto: das consideradas legalistas e centralizadas às mais combativas e de resistência direta.

${ }^{6} \mathrm{Ou}$, nos termos de Bourdieu (1990), que se constitua o "efeito oráculo", onde um indivíduo singular explora a transcendência do grupo monopolizando a verdade coletiva ao subsumir-se na figura do grupo ao mesmo tempo em que evoca na sua figura a coletividade, manipulando o grupo em nome do grupo em

Em Debat: Rev. Dig., ISSNe 1980-3532, Florianópolis, n. 12, p. 4-21, jun-dez, 2014.
} 
Do mesmo modo, o que pode parecer como ação perpetrada por indivíduos sem uma organização formal não necessariamente o é. Basta que observemos o consenso quase unânime em relação aos alvos escolhidos pelos black blocs para demonstrarem suas reivindicações e mensagens. O que leva a este consenso se não há um acordo prévio formalizado ou objetivos claramente definidos entre os participantes? A resposta para tal pergunta pode estar subscrita nas subculturas de resistência criadas e experienciadas por aqueles sujeitos submetidos à "coerção cotidiana" (the duress of the quotidian), na qual as condições dadas não são escolhidas, mas sim impostas, incluindose a exploração, a opressão, a expropriação, a violência policial, o abuso de poder, etc. Nesse caso, não há a necessidade de constituir-se uma organização formal para consubstanciar o que já encontra-se inscrito no ser social. Por outro lado, assim como ocorre nas resistências cotidianas descritas por Scott, o que talvez falte em termos de organização formal possa ser compensado em termos de flexibilidade e persistência. Contudo, se para a ação direta talvez bastem acordos silenciosos inscritos em uma subcultura de resistência, para a construção de propostas políticas há um desafio não apenas em termos de conteúdo programático, mas também de forma, dado o padrão de organização do ora quase grupo.

Outro elemento que precisa ser mencionado é a presença de fortes "traços anarquistas" seja na aparência ou na essência da tática dos black blocs. Embora não possamos correlacionar de forma linear e direta os black blocs ao "movimento anarquista" (até mesmo porque há várias correntes anarquistas e não um bloco coeso e homogêneo), tampouco é possível ignorar elementos evidentes seja em termos de filosofia, teoria e método seja em termos de símbolos, bandeiras e indumentária, que de algum modo influenciam este quase grupo.

Por fim, para entendermos as formas de ação coletiva é preciso levar em conta primeiramente a relação dialética entre autoridade (expressa na figura do Estado) e resistência (expressa nas lutas sociais) para que possamos compreender a interação entre os oponentes e as formas de resistência possíveis. Estas, por sua vez, dependem, em certo grau, das formas e níveis de repressão impostos. Se tomarmos estes elementos em consideração para pensarmos a atuação dos black blocs a partir das Jornadas de Junho de 2013 faz sentido o ato de cobrir o rosto para manter o anonimato e preservar a autonomia diante da sua identidade, evitando assim a identificação e criminalização dos

si mesmo. Por meio da imposição simbólica, o indivíduo se autoriza no grupo que, por sua vez, o autoriza a coagir o próprio grupo.

Em Debat: Rev. Dig., ISSNe 1980-3532, Florianópolis, n. 12, p. 4-21, jun-dez, 2014. 
manifestantes. A efemeridade do grupo ou o fato de não existirem black blocs nem antes nem depois dos protestos também está condicionada a esta marginalidade vivida pelos pseudocidadãos, que no seu cotidiano encontram-se submetidos a diversas formas de coerção e que, para manifestarem-se, necessitam adotar táticas que se adaptem às condições de repressão vividas. No caso dos protestos iniciados em junho de 2013, ficou claro que um elemento fundamental tanto para a mobilização das massas quanto para constituição de parte da oposição oferecida pelas mesmas foi a violência policial desproporcional e despropositada empregada contra os manifestantes que, por sua vez, apesar de acusados de incitarem a violência, defenderam-se com pedras e paus. Nesse sentido, a autoridade gerou e conformou a resistência que a desafiou e transformou, possibilitando o confronto apenas sob a proteção do anonimato.

Sendo assim, dificilmente veremos uma organização reivindicar-se enquanto porta-voz dos black blocs, não apenas porque a própria ideia de vocalização do "movimento" por líderes contrapõe-se à estratégia prática e quiçá ideológica deste quase grupo, como também porque sofreria óbvia e imediata perseguição política, como de fato se configurou nas prisões ocorridas em julho de 2014 de supostos "líderes de grupo black bloc" (VEJA, 2014), no marco dos protestos contra a Copa do Mundo. Portanto, é buscando observar os processos em movimento e em relação que devemos olhar para as novas formas de ação coletiva, atentando para o desenrolar dos fatos e para a interação entre estrutura e ação, ou o que Tilly chamará de "interação contínua entre os detentores de poder e seus desafiadores" (TILly, 1999, p.257). Finalmente, analisando-se o caso dos black blocs no cenário político recente brasileiro, nos parece que deve haver, do ponto de vista teórico, um esforço contínuo de reelaboração das categorias analíticas com base na práxis social enquanto critério da verdade, desapegando-se, quando necessário, dos tipos ideais como "movimento social", "ação coletiva" ou "resistência cotidiana", por entendermos que as fronteiras entre estas encontram-se cada vez mais nebulosas.

\section{Referências bibliográficas}

BOISSEVAN, J. (Sep. 1971), "Second thoughts on quasi groups, categories and coalitions", Man, New Series, Vol. 6, n. 3, pp. 468-472.

BOURDIEU, P. (1990), Coisas ditas, São Paulo, Brasiliense. 
FERREIRA, A. C. (2013), "Espontaneidade, Cultura e Política: o levante popular de junho no Brasil de um ponto de vista das ciências sociais". Disponível em: http://nepcpda.files.wordpress.com/2013/07/espontaneidade-politica-e-cultura.pdf, em 8-07-2013.

HARRIES-Jones, P. (1969), "Home-boy Ties and Political Organization in a Copperbelt Township", In J. C. Mitchell (ed.), Social Networks in Urban Situations, Manchester, University of Manchester Press.

LINCHBACH, M I. (1998), "Contending theories of contentious politics and the structure-action problem of social order”, Annu. Rev. Polit. Sci., 1, pp. 401-424.

MAYER, A. (1987), "A importância dos quase grupos no estudo das sociedades complexas", In B. Feldman-Bianco (org.), Antropologia das sociedades contemporâneas, São Paulo, Global.

MONSMA, K. ( $1^{\circ}$ semestre de 2000$)$, "James C. Scott e resistência cotidiana no campo: uma avaliação crítica”, BIB, Rio de Janeiro, n.49, pp.95-121.

NEVES, L (org.) (2010), "Direita para o social e esquerda para o capital: intelectuais da nova pedagogia da hegemonia no Brasil”, São Paulo, Xamã.

PASSETTI, E. (2013), "Prática anarquista aglutina gente em torno do insuportável", Entrevista concedida a Bruno Pontes, Disponível em: http://www.nusol.org/agora/agendanota.php?idAgenda=546, em 08-2013.

RANIERI, J.(1998), "Notas a respeito da concepção marxiana de método presente nos Grundrisse”, Perspectivas, São Paulo, v. 20/21, pp. 151-169.

Recife Resiste (2013), "Porque esconder nossos rostos", Disponível em: http://reciferesiste.org/porque-esconder-nossos-rostos/, em 17-06-2013.

SANTOS, R. S. P. (2012), "Resenha sobre 'O poder em movimento: movimentos sociais e confronto político", Sociologia \& Antropologia, v.02.03, pp.309 - 315.

SCOTT, J. (jan-jun 2002), "Formas cotidianas de resistência camponesa”, Raízes, 21, 1. 
TARROW, S. (2009), O poder em movimento: movimentos sociais e confronto político, Petrópolis, Vozes.

(2005), The new transnational activism, Cambridge, Cambridge University Press.

Thompson, E. P. (1987), A formação da classe operária inglesa, Rio de Janeiro, Paz e Terra.

Tilly, C. (1999), "From interactions to outcomes in social movements", In M. Giugni, D. Mc Adam, C. Tilly (ed.), How social movements matter, Minneapolis, University of Minesota Press.

UOL (2013), "Em dia de maior mobilização, protestos levam mais de 1 milhão de pessoas às ruas no Brasil", Disponível em: http://noticias.uol.com.br/cotidiano/ultimasnoticias/2013/06/20/em-dia-de-maior-mobilizacao-protestos-levam-centenas-demilhares-as-ruas-no-brasil.htm, em 21-06-2013.

Veja (2014), “Justiça aceita denúncia e decreta prisão de 23 black blocs”, Disponível em: http://veja.abril.com.br/noticia/brasil/justica-aceita-denuncia-e-decreta-prisao-de23-black-blocs, em 18-06-2014. 